\author{
Dorota PIWIŃSKA ${ }^{1}$ \\ Renata GRUCA-ROKOSZ ${ }^{2}$
}

\title{
WSKAŹNIKI POCHODZENIA I KIERUNKÓW PRZEMIAN MATERII ORGANICZNEJ W OSADACH DENNYCH ZBIORNIKÓW WODNYCH
}

\begin{abstract}
W osadach dennych zbiorników wodnych gromadzi się materia organiczna pochodzenia autochtonicznego i allochtonicznego. Pochodzenie materii organicznej można opisać za pomocą wskaźników, do których należą: skład izotopowy węgla $\delta^{13} \mathrm{C}$ i azotu $\delta^{15} \mathrm{~N}$, iloraz $\mathrm{C}: \mathrm{N}$, biomarkery lipidowe oraz pigmenty roślinne. Izotopy węgla i azotu występują powszechnie w środowisku w dużych ilościach. Stężenia mierzonych izotopów można opisać za pomocą delty $(\delta)$, wyrażanej w promilach [\%o]. Materia organiczna pochodzenia lądowego jest zubożona w izotop ${ }^{13} \mathrm{C}$ w porównaniu do materii organicznej pochodzenia autochtonicznego. Wskaźnik $\delta^{13} \mathrm{C}$ ulega zmianie podczas sedymentacji, mineralizacji oraz transformacji materii organicznej w środowisku wodnym. Natomiast wartość $\delta^{15} \mathrm{~N}$ zmienia się w zależności od przebiegu procesów denitryfikacji i odgazowania amoniaku. Materia organiczna jest również zróżnicowana pod względem stosunku C:N, gdzie dla autochtonicznej materii organicznej osiąga wartości mniejsze w porównaniu do materii pochodzenia allochtonicznego. $\mathrm{Z}$ kolei biomarkery lipidowe stanowią ważną grupę związków uznawanych za substancje wskaźnikowe, gdyż nie ulegają przeobrażeniom na przestrzeni lat. Stąd też wykorzystuje się je w badaniach ekologicznych i paleoekologicznych. Podobne właściwości wykazuje kolejna grupa biomarkerów, do której należą pigmenty roślinne. Dzielą się na trzy rodzaje: chlorofile, karotenoidy i fikobiliny. Analiza zawartości i składu materii organicznej w osadach dennych zbiorników wodnych za pomocą wskaźników jest skuteczną metodą pozwalającą na ocenę pochodzenia materii organicznej oraz produktywności biologicznej akwenów. Na podstawie wielkości rozkładu i stopnia zachowania wskaźników w osadach można wyznaczyć warunki środowiskowe panujące $\mathrm{w}$ zbiornikach wodnych $\mathrm{w}$ przeszłości. $\mathrm{W}$ artykule scharakteryzowano poszczególne wskaźniki pochodzenia materii organicznej i możliwości interpretacji w badaniach zbiorników wodnych.
\end{abstract}

Słowa kluczowe: materia organiczna, stabilne izotopy, biomarkery lipidowe, pigmenty roślinne, stosunek $\mathrm{C}: \mathrm{N}$

${ }^{1}$ Dorota Piwińska, Politechnika Rzeszowska, d.piwinska@prz.edu.pl

2 Autor do korespondencji / corresponding author: Renata Gruca-Rokosz, Politechnika Rzeszowska, ul. Powstańców Warszawy 6, 35-959 Rzeszów, tel. 17865 12 78, renatagr@ prz.edu.pl 


\section{Wprowadzenie}

Materia organiczna zgromadzona w osadach dennych może być pochodzenia allochtonicznego lub autochtonicznego [25]. Do źródeł allochtonicznych należą: spływy ze zlewni, działania antropogeniczne i terygeniczne. $Z$ kolei do źródeł autochtonicznych zalicza się planktoniczną i bentosową produkcję pierwotną. Znaczna ilość materii organicznej zostaje zdeponowana w osadach dennych dzięki zachodzącym procesom fizycznym, chemicznym i biologicznym [5, 23]. Wzrost aktywności antropogenicznej (industrializacja, urbanizacja i rolnictwo) powoduje intensywne dostarczanie materii organicznej do wyższych warstw osadów dennych. Materia ta ulega mineralizacji, co prowadzi do wzmożonego uwalniania azotu i fosforu z osadów. Skutkuje to pogorszeniem jakości zbiorników wodnych $[15,19,25]$. Rozpoznanie źródeł oraz losów materii organicznej w poszczególnych ekosystemach umożliwia prowadzenie właściwej gospodarki wodnej oraz odpowiedniej polityki ekologicznej w celu osiągnięcia dobrego stanu wód [25]. Do tego celu wykorzystuje się wskaźniki pochodzenia materii organicznej, do których należą: skład izotopowy węgla $\delta^{13} \mathrm{C}$ i azotu $\delta^{15} \mathrm{~N}$, stosunek C:N, biomarkery lipidowe oraz pigmenty roślinne [20, 33]. Analiza tych wskaźników w osadach dennych jest istotna w kontekście globalnego bilansu węgla i azotu, m. in. ze względu na emisję gazów cieplarnianych [8]. Rozróżnienie pochodzenia materii organicznej pozwala również określić przyczyny eutrofizacji i degradacji zbiorników wodnych. Gromadzenie się materii organicznej na powierzchni osadów dennych powoduje tworzenie się warstw (lamin) i może stanowić nieocenione archiwum przeszłych zmian środowiska $[3,24]$.

\section{Wskaźniki pochodzenia materii organicznej}

\subsection{Stosunek C:N}

Jednym z najczęściej wykorzystywanych wskaźników pochodzenia materii organicznej w osadach dennych jest stosunek węgla organicznego do azotu ogólnego (C:N) [14, 33].

Rośliny lądowe i glony są zróżnicowane pod względem wartości C:N. Glony bogate w białka charakteryzują się stosunkiem C:N w zakresie od 4 do 10 , natomiast rośliny lądowe bogate w celulozę - powyżej 20. Przyjmuje się, że jeżeli wartość C:N jest wyższa niż 12, to materia organiczna jest pochodzenia lądowego, natomiast gdy jest mniejsza od 8 - pochodzenia autochtonicznego [7]. Stąd też, dla fitoplanktonu wartość stosunku C:N mieści się w granicach $6,7-10,1$, a dla bakterii 2,6-4,3 [14].

Wielkość stosunku C:N jest również związana z procesami, które zachodzą w zbiornikach wodnych [14]. Stosunek C:N określa tempo mineralizacji materii organicznej. Im ten stosunek jest mniejszy, tym stopień mineralizacji wzrasta 
[32]. Dzieje się tak dlatego, że rozkład materii organicznej w znacznym stopniu redukuje zawartość węgla i substancji odżywczych w osadach dennych [33]. Rozkładany węgiel ulatnia się w postaci ditlenku węgla $\left(\mathrm{CO}_{2}\right)$ i metanu $\left(\mathrm{CH}_{4}\right)$, natomiast azot $\mathrm{w}$ postaci jonów amonowych $\left(\mathrm{NH}_{4}^{+}\right)$może zostać związany $\mathrm{z}$ minerałami w osadach [14]. Na zmianę stosunku C:N wpływa również utlenianie materii organicznej w kolumnie wody lub na powierzchni osadów dennych [33]. Tak więc, wartość stosunku C:N w osadach może być wskaźnikiem czasowych zmian w cyklu materii organicznej w ekosystemach wodnych [32].

\subsection{Skład izotopowy węgla $(\delta 13 \mathrm{C})$ i azotu $(\delta 15 \mathrm{~N})$}

Innymi, powszechnie wykorzystywanymi wskaźnikami pochodzenia materii organicznej w osadach dennych są stabilne izotopy węgla i azotu. Występują one naturalnie w środowisku w dużej ilości i biorą udział w przemianach biogeochemicznych. Najczęściej spotykanym sposobem określania stężeń mierzonych izotopów jest delta $\delta$, wyrażana w promilach [\%o]. Jest to pomiar względem laboratoryjnego wzorca przyjętego jako standard, kalibrowanego wobec standardu międzynarodowego, np. (1) [7]:

$$
\delta^{13} \mathrm{C}=\left(\frac{\mathrm{R}_{\mathrm{prb}}-\mathrm{R}_{\mathrm{std}}}{\mathrm{R}_{\mathrm{std}}}\right) \cdot 1000[\% \mathrm{o}]
$$

gdzie $\mathrm{R}$ jest stosunkiem zawartości izotopów ${ }^{13} \mathrm{C} /{ }^{12} \mathrm{C}$ odpowiednio w próbce $\left(\mathrm{R}_{\mathrm{prb}}\right)$ i we wzorcu $\left(\mathrm{R}_{\mathrm{std}}\right)$ [7].

Materia organiczna pochodzenia lądowego i wodnego różni się między sobą wartościami $\delta^{13} \mathrm{C}$ i $\delta^{15} \mathrm{~N}$ [19]. Wyższe wartości $\delta^{15} \mathrm{~N}$ stwierdza się w okresie lata ze względu na zwiększony udział materii organicznej pochodzenia fitoplanktonowego [16]. Za pomocą wskaźnika $\delta^{15} \mathrm{~N}$ w osadach dennych można określić szybkość sedymentacji allochtonicznej materii organicznej, źródła azotu dla fitoplanktonu oraz przebieg procesów rozkładu (denitryfikacja). Frakcjonowanie $\delta^{15} \mathrm{~N}$ podczas absorpcji i asymilacji azotu przez fitoplankton zależy od stężenia i form azotu nieorganicznego [33]. Głównymi procesami, w których dochodzi do znaczącego frakcjonowania izotopowego jest denitryfikacja i odgazowanie amoniaku, szczególnie silne w środowiskach alkalicznych stowarzyszone $\mathrm{z}$ efektem izotopowym na poziomie $34 \%$. W obu procesach dyskryminowany jest cięższy izotop azotu, prowadząc do znacznego wzrostu $\delta^{15} \mathrm{~N}$ pozostałego amoniaku i azotanów [14]. Wzrost wartości $\delta^{15} \mathrm{~N}$ materii organicznej świadczy o dostarczaniu azotu ciężkiego izotopowo $\left(\delta^{15} \mathrm{~N}=10-25 \%\right.$ o $)$ ze spływów powierzchniowych z terenów rolniczych oraz ze ścieków komunalnych [33].

Materia organiczna pochodzenia lądowego jest zubożona w izotop ${ }^{13} \mathrm{C}$ (zazwyczaj $\delta^{13} \mathrm{C}<-28 \%$ ) w porównaniu do materii organicznej pochodzenia autochtonicznego $\left(\delta^{13} \mathrm{C} \sim-22 \%\right.$ ) [13]. Rośliny pobierają węgiel z dwóch głównych źródeł: z atmosferycznego $\mathrm{CO}_{2}$ oraz wodnego $\mathrm{CO}_{2}$ i $\mathrm{HCO}_{3}{ }^{-}$[25]. Rośliny lądo- 
we, nazywane inaczej $\mathrm{C} 3$, mogą wiązać $\mathrm{CO}_{2}$ bezpośrednio z atmosfery, wykorzystując fotosyntetyczną ścieżkę Calvina-Bensona. Z kolei inne rośliny, zaliczane do $\mathrm{C} 4$, wiążą $\mathrm{CO}_{2}$, używając ścieżki Hatcha-Slacka [6, 7]. Materia organiczna produkowana przez roślinność lądową $\mathrm{i}$ glony słodkowodne $\mathrm{z} \mathrm{CO}_{2}$ atmosferycznego i rozpuszczonego $\left(\delta^{13} \mathrm{C} \sim-8 \%\right.$ o w rezultacie posiada niższe wartości $\delta^{13} \mathrm{C}$, gdzie dla roślin C3 wartość $\delta^{13} \mathrm{C}$ wynosi -38\%o- -22\%o [7, 21, 25]. Dla roślin $\mathrm{C} 4$ wartość wskaźnika $\delta^{13} \mathrm{C}$ wynosi średnio od -15 do $8 \%$. Zubożenie $\mathrm{w}$ węgiel ${ }^{13} \mathrm{C}$ w roślinach $\mathrm{z}$ grupy $\mathrm{C} 3 \mathrm{w}$ porównaniu do roślin $\mathrm{C} 4$ wynika głównie z tego, że enzymy roślin $\mathrm{C} 3$, które biorą udział w wiązaniu $\mathrm{CO}_{2}$ są bardziej dyskryminacyjne w stosunku do ${ }^{13} \mathrm{CO}_{2}$ niż enzymy roślin $\mathrm{C} 4[7,14]$. $\mathrm{Z}$ kolei fitoplankton preferuje pobieranie rozpuszczonego $\mathrm{CO}_{2}$, który jest zubożony $\mathrm{w}^{13} \mathrm{C}$ w stosunku do $\mathrm{HCO}_{3}{ }^{-}$o $8 \%$ - $11 \%$. Zakładając frakcjonowanie izotopowe $\varepsilon\left(\mathrm{CO}_{2} \rightarrow \mathrm{HCO}_{3}^{-}\right)$na poziomie $9 \%$, efektywne zubożenie materii organicznej w ${ }^{13} \mathrm{C}$ w porównaniu do rozpuszczonego $\mathrm{CO}_{2}$ mieści się w zakresie od $15 \%$ do $21 \%$ o $[14,25]$. W środowisku zdominowanym przez rośliny z grupy C3 wartość $\delta^{13} \mathrm{C}$ glonów słodkowodnych mieści się $\mathrm{w}$ granicach od $-35 \%$ do $-25 \%$ oraz $\delta^{15} \mathrm{~N}$ ok. 5\%o. Różnice $\mathrm{w} \delta^{13} \mathrm{C}$ wynikają głównie z odmiennych wartości $\delta^{13} \mathrm{C}$ rozpuszczonego węgla nieorganicznego (DIC - Dissolved Inorganic Carbon) wykorzystywanego przez fitoplankton i roślinność lądową. Wskaźnik $\delta^{13} \mathrm{C}$ zmienia się również podczas sedymentacji, degradacji i transformacji materii organicznej w środowisku wodnym [33].

\subsection{Biomarkery lipidowe}

Lipidy należą do grupy związków stymulujących wzrost, gromadzących energię, utrzymujących strukturę błony komórkowej oraz jej właściwości dynamiczne, a także stanowią substrat do syntezy kwasów tłuszczowych [22]. Są powszechnie obecne w środowisku, wykazują właściwości obojętne, przez co zachowują swoją trwałość w geologicznej skali czasu [26]. Stąd też, określone grupy lipidów noszą nazwę biomarkerów. Wykorzystuje się je m. in. w badaniach nad stanem troficznym wód, ponieważ określają źródło i przemiany materii organicznej w środowisku [11,22].

Biomarkery lipidowe są charakterystyczne dla poszczególnych organizmów w danym ekosystemie [1]. Mimo przeobrażeń jakim podlega materia organiczna, mogą przetrwać w osadach dennych nawet setki tysięcy lat $[6,28]$. Dlatego też, wykorzystywane są w badaniach paleoekologicznych i paleośrodowiskowych, gdzie ustala się źródła i transport biomarkerów lipidowych na obszarze zlewni oraz wpływ działalności człowieka na środowisko wodne na przestrzeni lat. Skład biomarkerów lipidowych w osadach dennych może zmieniać się pod wpływem produkcji pierwotnej i/lub transportu allochtonicznej materii organicznej [26].

Lipidy najprościej można podzielić na: proste, złożone oraz pochodne tłuszczów i sterole. Do tłuszczów prostych należą tłuszcze właściwe (estry gli- 
cerolu i kwasów tłuszczowych) i woski (cerydy), do tłuszczów złożonych - fosfolipidy i glikolipidy, a do pochodnych tłuszczów i steroli - wolne kwasy tłuszczowe i sterole [34].

W tabeli 1 przedstawiono w sposób szczegółowy wybrane grupy lipidów i pochodzenie poszczególnych związków.

Tabela 1. Wybrane grupy lipidów i pochodzenie poszczególnych związków (opracowane na podstawie [9])

Table 1. Groups of lipids and origin of particular compounds (based on [9])

\begin{tabular}{|c|c|}
\hline Lipidy & Pochodzenie \\
\hline $\begin{array}{c}\text { sterole } \\
\text { koprostanol } \\
\text { epikoprostanol } \\
\text { epicholestanol } \\
\text { cholesterol } \\
\text { cholestanol } \\
\text { stigmasterol } \\
\text { sitosterol } \\
\text { dinosterol } \\
\text { lanosterol }\end{array}$ & $\begin{array}{c}\text { odchody ludzkie } \\
\text { odchody ssaków wyższych } \\
\text { fototroficzne bakterie siarkowe } \\
\text { zooplankton } \\
\text { bruzdnica (glon), okrzemki } \\
\text { fitoplankton, rośliny naczyniowe, glony } \\
\text { rośliny wyższe, okrzemki } \\
\text { bruzdnica (glon) } \\
\text { grzyby, zwierzęta, bruzdnica (glon) }\end{array}$ \\
\hline 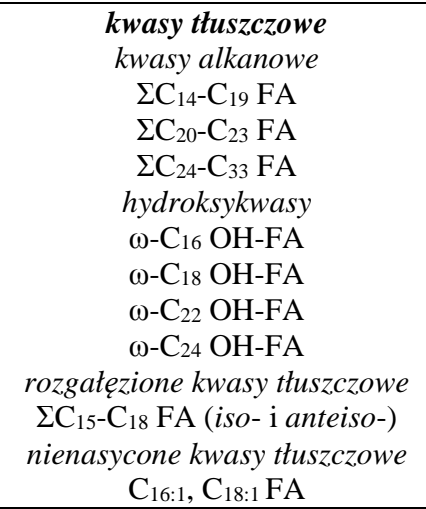 & $\begin{array}{c}\text { fitoplankton, bakterie } \\
\text { zróżnicowane } \\
\text { rośliny wyższe } \\
\text { kutyna, suberyna } \\
\text { kutyna } \\
\text { suberyna } \\
\text { suberyna } \\
\text { bakterie } \\
\text { fitoplankton, bakterie, mikroskopijne glony }\end{array}$ \\
\hline $\begin{array}{c}\text { n-alkanole } \\
\Sigma \mathrm{C}_{12}-\mathrm{C}_{19} \mathrm{OH} \\
\Sigma \mathrm{C}_{20}-\mathrm{C}_{23} \mathrm{OH} \\
\Sigma \mathrm{C}_{24}-\mathrm{C}_{33} \mathrm{OH} \\
\end{array}$ & $\begin{array}{l}\text { fitoplankton, bakterie } \\
\text { epifity, mikroskopijne glony } \\
\text { rośliny wyższe }\end{array}$ \\
\hline $\begin{array}{l}\text { n-alkany } \\
\Sigma \mathrm{C}_{12}-\mathrm{C}_{19} \\
\Sigma \mathrm{C}_{20}-\mathrm{C}_{25} \\
\Sigma \mathrm{C}_{26}-\mathrm{C}_{33}\end{array}$ & $\begin{array}{l}\text { fitoplankton, bakterie } \\
\text { makrofity } \\
\text { rośliny wyższe }\end{array}$ \\
\hline $\begin{array}{c}\text { inne } \\
\beta \text {-amyryna } \\
\text { tetrahymanol } \\
17 \beta(\mathrm{H}), 21 \beta(\mathrm{H}) \text {-bishomohopanol }\end{array}$ & $\begin{array}{c}\text { rośliny wyższe } \\
\text { orzęski, fototroficzne bakterie beztlenowe } \\
\text { bakterie glebowe }\end{array}$ \\
\hline
\end{tabular}

gdzie: FA (ang. fatty acids) - kwasy thuszczowe

OH-FA (ang. hydroxy fatty acids) - hydroksykwasy 
Krótkołańcuchowe kwasy alkanowe o liczbie atomów węgla n- $\mathrm{C}_{16}-\mathrm{n}-\mathrm{C}_{18}$ pochodzą głównie od fitoplanktonu, natomiast długołańcuchowe kwasy alkanowe (n- $\mathrm{C}_{24}-\mathrm{n}-\mathrm{C}_{32}$ ) świadczą o obecności wosku z liści roślin wyższych. Rozgałęzione kwasy tłuszczowe, do których należą iso- i anteiso- $\mathrm{C}_{15}$ FA (Fatty Acids kwasy tłuszczowe), występują w bakteriach żyjących zarówno w glebach, jak i osadach dennych. Z kolei nienasycone kwasy thuszczowe $\left(\mathrm{C}_{16: 1}\right.$ i $\mathrm{C}_{18: 1}$ ) występują w znacznych ilościach w fitoplanktonie. $\mathrm{C}_{18: 1}$ FA może zostać syntezowany przez bakterie glebowe. Związki tłuszczy nienasyconych są bardziej podatne na rozkład bakteryjny niż ich nasycone odpowiedniki. Brak tłuszczy nienasyconych, $\mathrm{z}$ wyjątkiem $\mathrm{C}_{18: 1} \mathrm{FA}$, może świadczyć o pobieraniu labilnej materii organicznej przez drobnoustroje. Kwasy hydroksylowe są głównym składnikiem kutyny i suberyny. Kutyna składa się głównie z hydroksykwasów o liczbie atomów węgla $\mathrm{C}_{16}$ i $\mathrm{C}_{18}$ i tworzy warstwę ochronną nadziemnych części roślin (woski roślinne). Suberyna zawiera natomiast znaczne ilości $\omega$ - hydroksykwasów $\mathrm{C}_{16}, \mathrm{C}_{22} \mathrm{i}_{24} \mathrm{i}$ występuje w materiale korzeniowym. $\mathrm{O}$ pochodzeniu lądowym materii organicznej świadczą n-alkany oraz n-alkanole długołańcuchowe n- $\mathrm{C}_{24}$ i n- $\mathrm{C}_{26}$. N-alkany krótkołańcuchowe wskazują na obecność glonów, a średniołańcuchowe o występowaniu makrofitów [6,9]. Sterole należą do lipidów błonowych, które występują w organizmach eukariotycznych (tj. zwierzęta, rośliny, grzyby i niektóre mikroorganizmy), natomiast są nieobecne w prokariontach (bakterie), z wyjątkiem bakterii metylotroficznych. Cholesterol i cholestanol występują powszechnie w organizmach żywych. Cholesterol może pochodzić od zooplanktonu (skorupiaki), bądź zoobentosu (mięczaki). Może również wchodzić w skład glonów (bruzdnic) oraz niektórych okrzemek. Sitosterol jest głównym sterolem roślin wyższych, jednakże może pojawiać się również w okrzemkach i mikroglonach. $Z$ kolei dinosterol i dinostanol pochodzą od glonów z grupy bruzdnic. Koprostanol należy do steroli występujących w odchodach człowieka, podczas, gdy epikoprostanol jest produktem przemiany materii ssaków wyższych. Oba związki są zatem często stosowane jako wskaźnik zanieczyszczenia ściekami gleb i osadów dennych. Epicholestanol jest wytwarzany $\mathrm{z}$ cholesterolu przez bakterie w warunkach silnie anoksycznych. Znaczne ilości epicholestanolu mogą pojawiać się $\mathrm{w}$ fototroficznych bakteriach siarkowych żyjących w strefie osad-woda w warunkach beztlenowych. Pozostałe lipidy, pochodzą z następujących źródeł: $17 \beta(\mathrm{H}), 21 \beta(\mathrm{H})$ - bishomohopanol znajduje się w bakteriach żyjących w glebach, tetrahymanol w orzęskach, a także w beztlenowych fototroficznych bakteriach purpurowych Phodopseudomonas palustris, natomiast $\beta$-amyryna stanowi składnik roślin wyższych $[9,24]$.

\subsection{Pigmenty roślinne}

Pigmenty roślinne są obecne zarówno w lądowych, jak i wodnych organizmach fotosyntetyzujących i mogą być wykorzystywane jako wskaźniki pochodzenia materii organicznej w ekosystemach wodnych oraz w badaniach limno- 
logicznych i paleolimnologicznych [4]. Wyróżnia się trzy grupy: chlorofile, karotenoidy i fikobiliny. Chlorofile uchodzą za indykatory biomasy fitoplanktonu, z kolei karotenoidy za wskaźniki jego taksonomicznego zróżnicowania [2]. Dodatkowo, chlorofile stanowią główny barwnik asymilacyjny roślin zbiorników słodkowodnych. Istnieje pięć rodzajów tych barwników: a, b, c, d i e. Spośród wszystkich chlorofili jedynie chlorofil-a posiada zdolność kierowania zaabsorbowanej energii świetlnej na drogę przemian chemicznych, a pozostałe barwniki pełnią tylko rolę pomocniczą [30]. Pigmenty w wodzie i osadach zbiorników wodnych pochodzą od glonów planktonowych i bentosowych, bakterii fototroficznych, makrofitów wodnych oraz w mniejszej części od niezdegradowanych pigmentów roślinności allochtonicznej [18]. Niektóre grupy fitoplanktonowe i bakterioplanktonowe zawierają specyficzne pigmenty, które stosuje się jako jednoznaczne wskaźniki. Przykładowo, występowanie okrzemek można stwierdzić poprzez obecność fucoxanthiny, natomiast cyjanobakterii poprzez występowanie scytonemy, myxoxanthophylu i echinenony. Chlorofil $b$ i luteina znajdują się zarówno w Chlorophyceae, jak i w roślinach lądowych oraz w wodnych makrofitach. W związku z tym, stosunek węgiel/pigment jest znacznie niższy dla fitoplanktonu, niż dla roślin wyższych. Stąd też, istnieje możliwość rozróżnienia allochtonicznej materii organicznej od autochtonicznej [4].

Pigmenty słabo rozpuszczają się w wodzie, charakteryzują się dużą zdolnością absorpcji promieniowania słonecznego. Poszczególne rodzaje pigmentów absorbują falę o różnej długości, co umożliwia wyznaczenie ich składu metodami fotometrycznymi. Macierzyste cząsteczki pigmentów są mało trwałe w środowisku. Ulegają rozkładowi w wodzie i powierzchniowej warstwie osadów pod wpływem różnych czynników środowiskowych, tworząc dziesiątki derywatów. Karotenoidy stanowią grupę pigmentów bardziej odpornych na degradację, z kolei mniej odporne są chlorofile, z których najmniej stabilny jest chlorofil typu a i c $[18,28]$. Produkty degradacji chlorofili (feopigmenty) są zdecydowanie bardziej trwałe w środowisku, co umożliwia ich wykrycie nawet po upływie tysięcy lat [27].

Pomimo, że pigmenty roślinne są podatne na degradację, uważane są za indykatory $\mathrm{w}$ badaniach ekologicznych i paleoekologicznych. W połączeniu $\mathrm{z}$ analizą okrzemek uznaje się je za wskaźnik obfitości glonów w ekosystemie wodnym, a także za wskaźnik jego produktywności [29]. Takim wskaźnikiem określającym wielkość produkcji pierwotnej jest chlorofil [12]. Produktywność zbiorników wodnych, pomijając uwarunkowania biologiczne, zależy także od wielu czynników abiotycznych, m. in. od warunków klimatycznych, hydrologicznych, dostępności światła, a przede wszystkim od dostawy biogenów. Ich wpływ na ekosystem zbiornika wodnego wiąże się znacząco z przebiegiem procesów przyrodniczych i antropogenicznych, które zachodzą w ich zlewniach. Dlatego, też pigmenty roślinne mogą być również indykatorami monitorującymi zmiany klimatu oraz przebieg procesów geomorfologicznych, co powoduje, że są one również skutecznym narzędziem w rekonstrukcjach paleogeograficznych [28]. 
Pigmenty roślinne utrzymują się przez dłuższy czas w głębokich, słabo natlenionych, chłodnych oraz pozbawionych światła częściach zbiorników wodnych, gdzie na dnie zalegają osady bogate w materię organiczną i frakcję ilastą [31]. Pigmenty w osadach zachowują swoją trwałość dzięki zwiększonej sedymentacji osadów, które szybko izolują już zdeponowane pigmenty od aktywnej chemicznie i biologicznie strefy kontaktowej osad-woda [10]. Niekorzystne warunki, z punktu widzenia akumulacji pigmentów w osadach dennych, występują w płytkich, zasobnych $w$ tlen oraz dobrze oświetlonych i intensywnie mieszanych partiach zbiorników wodnych. W środowiskach tych, duża część chloropigmentów może ulec rozkładowi nawet do produktów bezbarwnych [17].

\section{Podsumowanie}

Materia organiczna zgromadzona w osadach dennych zbiorników wodnych charakteryzuje się zróżnicowanym pochodzeniem, które określa się za pomocą omówionych w artykule wskaźników: skład izotopowy węgla $\delta^{13} \mathrm{C}$ i azotu $\delta^{15} \mathrm{~N}$, stosunek C:N, biomarkery lipidowe oraz pigmenty roślinne. Ich analiza pozwala wyznaczyć pochodzenie materii organicznej, zarówno w sposób ogólny (allochtoniczna, autochtoniczna), jak i szczegółowy (obecność substancji i związków przypisanych do określonych grup roślin i organizmów). Dodatkowo, ustalenie składu materii organicznej w osadach dennych oraz wielkości rozkładu i stopnia zachowania wskaźników pozwala scharakteryzować warunki środowiskowe panujące w zbiornikach wodnych obecnie i w przeszłości.

\section{Literatura}

[1] Aarons A., Using lipid biomarkers to determine changes in community structure and ecological processes occurring in the meromictic Sider's Pond, Falmouth, MA, 2011, s. 1-14.

[2] Bianchi T.S., Biogeochemistry of estuaries. Oxford University Press, New York 2007.

[3] Chodyka M., Nitychoruk J., Welc F., Rogóż A., Lubańska Z., Grudniewski T., Wpływ zmian klimatu na osadnictwo prehistoryczne Mazur w kontekście badań osadów jeziornych, Czasopismo Inżynierii Lądowej, Środowiska i Architektury Journal Of Civil Engineering, Environment And Architecture, JCEEA, t. XXXIII, z. 63 (3/16), 2016, s. 43-50, DOI:10.7862/rb.2016.184.

[4] de Junet A., Abril G., Guerin F., Billy and de Wit R.: Sources and transfers of particulate organic matter in a tropical reservoir 9Petit Saut, French Guiana): a multitraces analysis using $\delta^{13} \mathrm{C}, \mathrm{C} / \mathrm{N}$ ratio and pigments, Biogeosciences Discussions, nr 2, 2005, s. 1159-1196.

[5] Gireeshkumar T.R., Deepulal P.M., Chandramohanakumar N., Distribution and sources of sedimentary organic matter in a tropical estuary, south west coast of India (Cochin estuary): A baseline study. Marine Pollution Bulletin, nr 66, 2013, s. 239-245. 
[6] Gong W., Zhang Z., Lipid biomarkers and organic matter carbon isotopes in estuarine sediments as proxies for evaluating seawater intrusion. Estuarine, Coastal and Shelf Science, nr 155, 2015, s. 38-46.

[7] Gruca-Rokosz R., Dynamika węglowych gazów cieplarnianych w zbiornikach zaporowych - mechanizmy produkcji, emisja do atmosfery, Oficyna Wydawnicza Politechniki Rzeszowskiej, Rzeszów 2015.

[8] Gruca-Rokosz R., Zbiorniki zaporowe jako źródło emisji gazów cieplarnianych, Inżynieria i Ochrona Środowiska, t. 15, nr 1, 2012, s. 51-65.

[9] Holtvoeth J., Vogel H., Wagner B., Wolff G.A., Lipid biomarkers in Holocene and glacial sediments from ancient Lake Ohrid (Macedonia, Albania). Biogeosciences, nr 7, 2010, s. 3473-3489.

[10] Hurley J.P., Armstrong D.E., Fluxes and transformations of aquatic pigments in Lake Mendota, Wisconsin. Limnol. Oceanogr., nr 35/2, 1990, s. 384-398.

[11]Jeffreys R. M., Wolff G. A., Murty S. J., The trophic ecology of key megafaunal species at the Pakistan Margin: Evidence from stable isotopes and lipid biomarkers. Deep-Sea Research I, nr 56, 2009, s. 1816-1833.

[12] Kajak Z., Hydrobiologia-Limnologia. Ekosystemy wód śródlądowych, Państwowe Wydawnictwo Naukowe, Warszawa 1998.

[13] Ke Z., Tan Y., Huang L., Zhao C., Jiang X., Spatial distributions of $\delta^{13} \mathrm{C}, \delta^{15} \mathrm{~N}$ and $\mathrm{C} / \mathrm{N}$ ratios in suspended particulate organic matter of a bay under serious anthropogenic influences: Daya Bay, China. Marine Pollution Bulletin, nr 114, 2017, s. 183-191.

[14] Klisch M., Praca doktorska, pt. Kompleksowe badania izotopowe laminowanych osadów jeziora Gościąż. Akademia Górniczo-Hutnicza im. Stanisława Staszica w Krakowie, Wydział Fizyki i Informatyki Stosowanej, Kraków 2009.

[15] Kostecki M., Suschka J., The successful results of Pławniowice reservoir (Upper Silesia region - South of Poland) restoration by hypolimnetic withdrawal, vol. 39, no. 1, 2013, pp. 17-25, DOI: 10.2478/aep-2013-0004.

[16] Koszelnik P., Źródła i dystrybucja pierwiastków biogennych na przykładzie zespołu zbiorników zaporowych Solina-Myczkowce, Oficyna Wydawnicza Politechniki Rzeszowskiej, Rzeszów 2009.

[17] Kowalewska G., Szymczak M., Influence of selected abiotic factors on the decomposition of chlorophylls. Oceanologia, nr 43/3, 2001, s. 315-328.

[18] Leavitt P.R., A review of factors that regulate carotenoid and chlorophyll deposition and fossil pigment abundance. J. Paleolimnology, nr 9, 1993, s. 109-127.

[19] Lee Y., Hur J., Shin K.-H., Characterization and source identification of organic matter in view of land uses and heavy rainfall in the Lake Shihwa, Korea. Marine Pollution Bulletin, nr 84, 2014, s. 322-329.

[20]Lin T., Ye S., Ma C., Ding X., Brix H., Yuan H., Chen Y., Guo Z., Sources and preservation of organic matter in soils of the wetlands in the Liaohe (Liao River) Delta, North China. Marine Pollution Bulletin, nr 71, 2013, s. 276-285.

[21]Liu D., Li X., Emeis K.-C., Wang Y., Richard P., Distribution and sources of organic matter in surface sediments of Bohai Sea near the Yellow River Estuary, China. Estuarine, Coastal and Shelf Science, nr 165, 2015, s. 128-136.

[22]Loh A. N., Canuel E. A., Bauer J. E., Potential source and diagenetic signatures of oceanic dissolved and particulate organic matter as distinguished by lipid biomarker distributions. Marine Chemistry, nr 112, 2008, s. 189-202. 
[23] Maj K., Koszelnik P., Metody zagospodarowania osadów dennych, Czasopismo Inżynierii Lądowej, Środowiska i Architektury Architektury - Journal Of Civil Engineering, Environment And Architecture, JCEEA, t. XXXIII, z. 63(2/I/16), 2016, s. 157-169, DOI: $10.7862 / \mathrm{rb} .2016 .118$.

[24] Naher S., Praca doktorska, pt. Sedimentary lipid biomarkers and trace metals as indicators for past hypoxia and eutrophication. Dipl. - Geol., Johannes Gutenberg University of Mainz, Germany 2012.

[25] Remeikaite-Nikiene N., Lujaniene G., Malejevas V., Banseviciute R., Zilius M., Garnaga-Budre G., Stankevicius A., Distribution and sources of organic matter in sediments of the south-eastern Baltic Sea. Journal of Marine Systems, nr 157, 2016, s. $75-81$.

[26] Sarkar S., Wilkes H., Prasad S., Brauer A., Riedel N., Stebich M., Basavaiah N., Sachse D., Spatial heterogeneity in lipid biomarker distributions in the catchment and sediments of a crater lake in central India. Organic Geochemistry, nr 66, 2014, s. $125-136$.

[27] Scheer H., Structure and Occurrence of Chlorophylls. CRC Press, Boca Raton, Florida 1991, s. 3-30.

[28] Sigareva L. E., Gierszewski P., Zakonnov V. V., Fosylne pigmenty roślinne biomarkerami stanu środowiska ekosystemów wodnych. Landform Analysis, nr 12, 2010, s. 99-108.

[29] Smol J.P., Pollution of lakes and rivers: A paleoenvironmental perspective. Oxford University Press, New York 2002.

[30] Szyjkowski A., Barwniki roślinne i ich znaczenie w rozwoju fitoplanktonu. Ochrona Środowiska, nr 5/3-4, 1983, s. 47-53.

[31] Szymczak-Żyła M., Kowalewska G., Chloropigments a in the Gulf of Gdańsk (Baltic Sea) as markers of the state of this environment. Marine Pollution Bulletin, nr 55, 2007, s. 512-528.

[32] Tarnawski M., Baran A., Jasiewicz C., Ocena właściwości fizyczno-chemicznych osadów dennych zbiornika Chańcza. Proceedings of ECOpole, nr 6(1), 2012, s. 1-7, DOI: 10.2429/proc.2012.6(1)042.

[33] Wang Y., Liu D., Richard P., Li X., A geochemical record of environmental changes in sediments from Sishili Bay, northern Yellow Sea, China: Antropogenic influence on organic matter sources and composition over the last 100 years. Marine Pollution Bulletin, nr 77, 2013, s. 227-236.

[34] https://www.pum.edu.p1/_data/assets/pdf_file/0007/83068/Lipidy-org-BMwyklad-9.pdf (dostęp: 23 styczeń 2017 r.).

\section{INDICATORS OF ORIGIN AND DIRECTIONS OF TRANSFORMATION OF ORGANIC MATTER IN SEDIMENTS OF WATER RESERVOIRS}

\section{S u m m a r y}

Autochthonous and allochthonous organic matter is accumulated in sediments of water reservoirs. Organic matter can be described as indicators, such as: isotopic signatures of $\delta^{13} \mathrm{C}$ and $\delta^{15} \mathrm{~N}, \mathrm{C}: \mathrm{N}$ ratio, lipid biomarkers and plant pigments. A large amount of carbon and nitrogen isotopes widely occur in the environment. Concentrations of the measured isotopes can be described 
with $\delta$ delta, expressed in \%o. Allochthonous organic matter is depleted in ${ }^{13} \mathrm{C}$ isotope in comparison to autochtchonous organic matter. $\delta^{15} \mathrm{~N}$ value changes according to denitrification process and ammonia degasification. Organic matter is also diverse in terms of $\mathrm{C}: \mathrm{N}$ ratio and for autochthonous organic matter achieves values less than for allochthonous organic matter. Lipid biomarkers form an important group of compounds which are considered as indicators, because they do not undergo any transformation over the years. Thus they are used in ecological and paleoecological research. Another group of biomarkers to which plant pigments belongs has similar properties. Plant pigments are divided into three types: chlorophylls, carotenoids and phycobilins. Organic matter content and composition analysis in sediments of water reservoirs with indicators is an effective method which allows to assess organic matter origin and biological productivity of water reservoirs. On the basis of decomposition level and degree of conservation of indicators in sediments we can determine environmental conditions in water reservoirs in the past. In this scientific paper, particular indicators of organic matter origin and possibilities of interpretation in water ecosystem research were characterized.

Keywords: organic matter, stable isotopes, lipid biomarkers, plant pigments, C:N ratio

Przestano do redakcji: 16.01.2017 r.

Przyjęto do druku: 31.03.2017 r. 